www.jmscr.igmpublication.org

Impact Factor 5.84

Index Copernicus Value: 83.27

ISSN (e)-2347-176x ISSN (p) 2455-0450

crossref DOI: https://dx.doi.org/10.18535/jmscr/v5i1.48

\author{
Journal Of Medical Science And Clinical Research \\ IGM Publication \\ An official Publication of IGM Publication
}

\title{
A Study to Assess Chochleovestibular Symptoms in Acquired Hypothyroidism
}

\author{
Authors \\ Dr Anil HT ${ }^{1}$, Dr Ganga.J.Kamath ${ }^{2}$ \\ ${ }^{1}$ Professor, Dept of ENT, Kempegowda Institute of Medical Sciences, Bangalore, INDIA \\ ${ }^{2}$ Postgraduate, Dept of ENT, Kempegowda Institute of Medical Sciences, Bangalore, INDIA \\ Email: ganga.veena@gmail.com, Mob No: 9740192474
}

\begin{abstract}
Objective: To evaluate the prevalence of cochleovestibular $(C V)$ symptoms in acquired hypothyroidism and to establish a relation between $C V$ symptoms and duration of hypothyroidism.

Materials and Methods: An observational study of 100 patients with diagnosis of hypothyroidism on treatment and with euthyroid state. Parameters studied: gender, duration of hypothyroidism, CV symptoms, pure tone audio metry (PTA).

Results: $82 \%$ were women with the predominance of the age between 30-40 years $(34.6 \pm 2.87)$.The mean duration of hypothyroidism was 3 yrs $(2.8 \pm 1.70)$. 56\% had the diagnosis of hypothyroidism for more than 3 years. $63 \%$ of the study group had no symptoms, $21 \%$ complained of subjective hearing loss, $6 \%$ tinnitus and $2 \%$ vertigo only, $2 \%$ had hearing loss, vertigo and tinnitus, while $6 \%$ had tinnitus with hearing loss only. Based on PTA, 63\% of hypothyroid patients had normal hearing,19.5\% cases had sensorineural hearing loss (SNHL), 12\% mixed hearing loss(MHL), and 5\% had conductive hearing loss (CHL).Mild degree of hearing impairment was present in majority (27\%), moderate in $8.4 \%$ and $2 \%$ had moderately severe hearing loss. None had severe and profound hearing loss.

Conclusion: It was found that patients with acquired hypothyroidism on regular treatment had hearing impairment with predominance of SNHL followed by mixed and conductive type, ranging from mild to moderate in severity. Vestibular system was found to be affected minimally. It was found that there was no relation between duration of hypothyroidism with euthyroid status and CV symptoms.

Keywords: hearing loss, hypothyroidism, pure tone audiometry.
\end{abstract}

\section{Introduction}

Hearing loss was first reported in acquired hypothyroidism in $1907^{[1]}$. The prevalence of hypothyroidism in India is $11 \%$, compared with only $2 \%$ in the UK and $4.6 \%$ in the USA. ${ }^{[2]}$.

In 1974, Ritter stressed that hearing loss can be the most common otolaryngological manifestation of congenital and acquired hypothyroidism, and auditory symptoms may happen alone or in association with vertigo and tinnitus. ${ }^{[3]}$ The real incidence of hearing loss in patients with hypothyroidism is still uncertain, and it may affect $25 \%$ of the patients with acquired hypothyroidism and $35-50 \%$ of the patients with congenital hypothyroidism. ${ }^{[4,5]}$

It is known that in hypothyroidism there is reduction in cell energy production, compromising the microcirculation and, consequently, 
oxygenation and the metabolism of the involved $\operatorname{organs}^{[6]}$. In addition, $\mathrm{T} 4$ also acts as a neurotransmitter. Thus it is believed that under hypothyroidism, hearing impairment can originate in the cochlea,in the central auditory pathways and/or in the retrocochlear region. ${ }^{[7]}$ Based on PTA only, it has been reported to vary from $11.5 \%$ to $95 \%$ of cases investigated. ${ }^{[8,9,10]}$

The aim of the present study was to estimate the prevalence of $\mathrm{CV}$ symptoms in acquired hypothyroidism and to establish a relation between $\mathrm{CV}$ symptoms and duration of hypothyroidism.

\section{Material and Methodology}

An observational study was conducted on 100 subjects diagnosed with hypothyroidism on treatment and with euthyroid state from September 2015 to May 2016 at department of ENT, in Kempegowda institute of medical sciences, Bangalore. The study and consent forms were approved by institutional ethics committee.

A detailed history regarding the onset of hypothyroidism, duration of disease, presence of CV symptoms (hearing loss, tinnitus and vertigo) were obtained. Clinical evaluation was done with otoscopic examination, gait and positional tests such as Dix Hallpike manoeuvre, Romberg's test and Unterberger test. T3 T4 and TSH levels were tested. The hearing acuity was examined with PTA evaluation.

Subjects with other known causes of hearing loss such as ototoxicity, noise induced hearing loss, chronic serous otitis media, presbyacusis and any other known cause of hearing impairment were excluded from the study. Patients with any previous thyroid surgeries or malignancy, subclinical hypothyroidism, newly detected hypothyroidism and not on treatment were excluded from the study. Patients with other comorbidities such as hypertension and diabetes mellitus were excluded from the study.

To assess the relation between $\mathrm{CV}$ symptoms and duration of hypothyroidism, the patients were divided into two groups based on the mean duration of hypothyroidism.

The audiometric results were classified into type and degree. The losses were classified in: conductive (airway thresholds above $25 \mathrm{~dB}$ and the normal bone conduction threshold, with an airbone gap); mixed (air and bone conduction thresholds above $25 \mathrm{~dB}$, with air-bone gap) and sensorineural (air and bone conduction thresholds above $25 \mathrm{~dB}$, without air-bone gap). Concerning the grade, the hearing losses were classified into: mild (thresholds between 26 and $40 \mathrm{~dB}$ ); moderate (thresholds between 41 and $55 \mathrm{~dB}$ ); moderately severe (thresholds between 56-70 Db) severe (thresholds between 71 and $90 \mathrm{~dB}$ ) and profound (thresholds above $91 \mathrm{~dB}){ }^{[1]}$

The statistical analysis was performed on the set of all eligible subjects enrolled in the study according to the study protocol. The prevalence of hypothyroidism and other thyroid disorders was summarized as counts and percentages. A chi square test was used to assess the relation between duration of hypothyroidism and CV symptoms.

\section{Results}

The mean age of the study patients ( 82 females and 18 males) was $34.6 \pm 2.87$ years, with a range of 20 to 60 years. Age distribution of the study patients was as follows: $16 \%$ were aged between 20 to 30 years, $42 \%$ were aged $30-40$ years, $24 \%$ were aged $40-50$ years and $18 \%$ were $50-60$ years of age.

In our study $63 \%$ of the study group had no symptoms, however $21 \%$ complained of subjecttive hearing loss, $6 \%$ tinnitus and $2 \%$ vertigo, $2 \%$ had hearing loss, vertigo and tinnitus, while $6 \%$ had tinnitus with hearing loss only.(Table: 1) (fig: 1)

The mean duration of patients with hypothyroidism was $2.8 \pm 1.70$ years, $56 \%$ having diagnosis of hypothyroidism for more than 3 years ((Table:2a) However, no statistically significant difference $(\mathrm{p}=0.808)$ was found between duration of hypothyroidism and CV symptoms.(Table:2b) 


\section{JMSCR Vol||05||Issue||01||Page 15486-15491||January}

On PTA, out of 200 ears tested, 127 (63\%) had hearing sensitivity within normal limits, 54 ears (27\%) had mild hearing loss, 17 (8.5\%) moderate hearing loss and $2(1 \%)$ had moderately severe hearing loss. In our study, none had severe and profound hearing loss. (Table: 3) (Fig: 2)

Based on the type of hearing loss, 127 had normal hearing (63.5\%), 39 had SNHL(19.5\%) ,24 had mixed (12\%) and 10 had conductive (5\%) hearing loss.(Table:4 )(fig:3)

Table 1. List of the cochleovestibular symptoms assessed in hypothyroid patients

\begin{tabular}{|l|c|}
\hline \multicolumn{1}{|c|}{ Symptoms } & $\begin{array}{c}\text { Hypothyroid patients } \\
\mathbf{n}(\%)\end{array}$ \\
\hline No symptoms & $63(63 \%)$ \\
\hline Hearing loss & $21(21 \%)$ \\
\hline Tinnitus & $6(6 \%)$ \\
\hline Vertigo & $2(2 \%)$ \\
\hline $\begin{array}{l}\text { Hearing loss,tinnitus and } \\
\text { vertigo }\end{array}$ & $2(2 \%)$ \\
\hline Hearing loss and tinnitus & $6(6 \%)$ \\
\hline
\end{tabular}

Table 2a: cochleovestibular symptoms with duration of disease.

\begin{tabular}{|c|c|c|}
\hline \multirow[t]{2}{*}{ symptoms } & \multicolumn{2}{|c|}{ Duration of disease } \\
\hline & $\begin{array}{c}<3 \mathrm{yrs} \\
\mathrm{n}(\%)\end{array}$ & $\begin{array}{l}>3 y r s \\
\mathrm{n}(\%)\end{array}$ \\
\hline $\begin{array}{l}\text { No } \\
\text { symptoms }\end{array}$ & $30(30 \%)$ & $41(41 \%)$ \\
\hline Hearing loss & $8(8 \%)$ & $11(11 \%)$ \\
\hline Tinnitus & $3(3 \%)$ & $3(3 \%)$ \\
\hline Vertigo & $1(1 \%)$ & $1(1 \%)$ \\
\hline $\begin{array}{l}\text { Hearing loss, } \\
\text { tinnitus and } \\
\text { vertigo }\end{array}$ & $0(0 \%)$ & $0(0 \%)$ \\
\hline $\begin{array}{l}\text { Hearing loss } \\
\text { and tinnitus }\end{array}$ & $2(2 \%)$ & $0(0 \%)$ \\
\hline
\end{tabular}

Table 2b: cochleovestibular symptoms with duration of disease.

\begin{tabular}{|l|c|c|}
\hline & $\begin{array}{c}\text { DURATION OF DISEASE } \\
<3 \text { YEARS }\end{array}$ & $<$ Y YEARS \\
\hline $\mathbf{N}$ & 6 & 6 \\
\hline$\sum \mathbf{X}$ & 44 & 56 \\
\hline Mean & 7.3333 & 9.3333 \\
\hline$\sum \mathbf{X}^{\mathbf{2}}$ & 978 & 1812 \\
\hline Std.Dev. & 11.4484 & 16.0582 \\
\hline
\end{tabular}

The $p$-value is $\quad .808845$. The result is not significant at $p<.05$.

Table 3. Grade of hearing loss based on Pure tone audiometry

\begin{tabular}{|l|c|}
\hline Hearing loss(dB) & $\begin{array}{c}\text { Hypothyroid patients } \\
\text { (200 ears) } \\
\text { n(\%) }\end{array}$ \\
\hline Normal & $127(63 \%)$ \\
\hline Mild( 25-40) & $54(27 \%)$ \\
\hline Moderate(41-55) & $17(8.5 \%)$ \\
\hline Moderately severe(56-70) & $2(1 \%)$ \\
\hline Severe(71-90) & $0(0 \%)$ \\
\hline Profound(>90) & $0(0 \%)$ \\
\hline
\end{tabular}

Table 4: Type of hearing loss based on Pure tone audiometry.

\begin{tabular}{|c|c|}
\hline Type of hearing loss & $\begin{array}{c}\text { Hypothyroid patients } \\
\text { (200 ears) } \\
\mathrm{n}(\%)\end{array}$ \\
\hline Conductive & $10(5 \%)$ \\
\hline Mixed & $24(12 \%)$ \\
\hline Sensorineural & $39(19.5 \%)$ \\
\hline Normal & $127(63 \%)$ \\
\hline
\end{tabular}

fig 1: List of the cochleovestibular symptoms assessed in hypothyroid patients

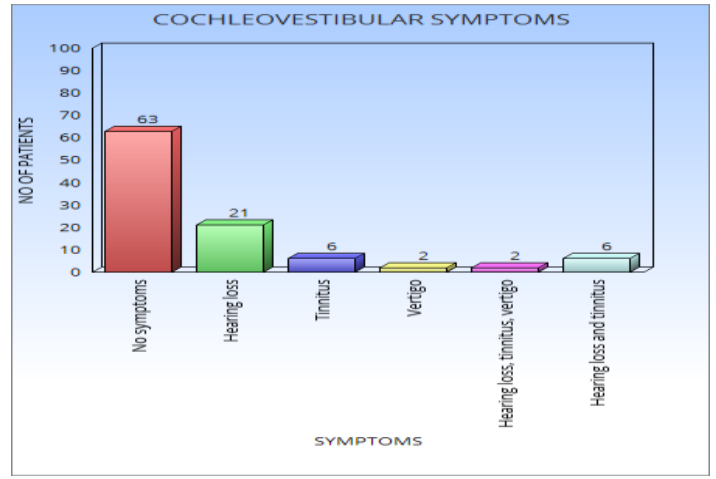


fig 2: Grade of hearing loss based on Pure tone audiometry

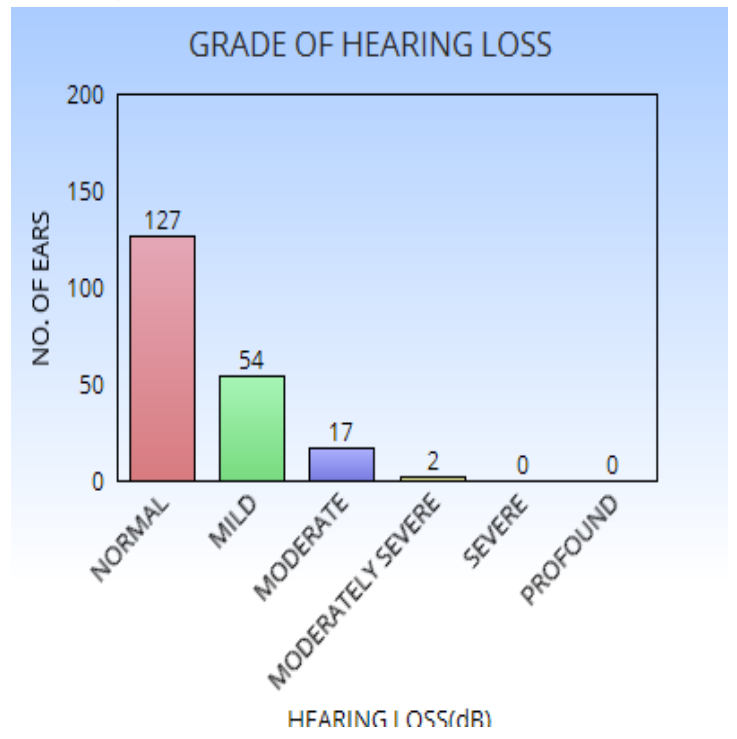

Fig 3: Type of hearing loss based on Pure tone audiometry

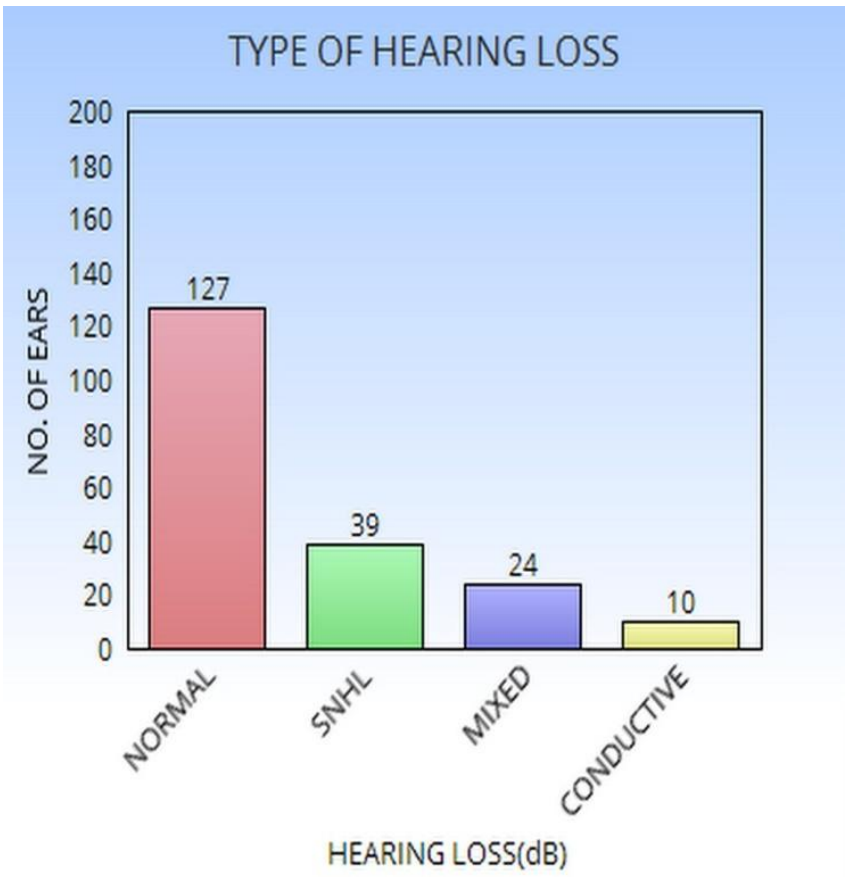

\section{Discussion}

Majority of the patients in the present study were $30-40$ years age group (42\%). $82 \%$ of hypothyroid patient were females .The Myxoedema Committee of the clinical society of London(1880) reported that the disease affects women much more frequently than men, and the subjects are of the middle age.

The analysis of cochleovestibular symptoms showed that $63 \%$ of the hypothyroid patients did not have any symptoms. In our study we found $21 \%$ hypothyroid patients had subjective hearing loss. Subjective hearing loss in patients may be either due to actual conductive or sensorineural hearing loss or slowed mentation during hypothyroid state may be interpreted by the patients as subjective hearing loss as suggested by MC Mohan (1947) $)^{[11]}$.

Tinnitus was present in 12 (12\% )of hypothyroid patients, Similar findings were noted by Anand et al (1989) ${ }^{[12]}$ and Bhatia et $\operatorname{al}(1977)^{[13]}$ who reported the incidence of tinnitus to be around $15 \%$ in hypothyroid patients. Tinnitus is a frequent complaint in the general population ,affecting from 35 to $40 \%$ of adults and it has multiple causes. In our study vertigo was complained by $2 \%$ of the hypothyroid patients. The incidence of dizziness in literature has been reported to be as low as absent to as high as $75 \%$ by different workers. Bhatia et al showed dizziness was present in $6.66 \%$. However studies conducted by Howarth $\mathrm{AE}$ et al ${ }^{[14]}$ reported that no patient complained of vertigo.

On PTA in hypothyroid patients, out of 60 ears examined, hearing within normal limits was present in $63.5 \%$ of ears, while $36.5 \%$ had hearing loss, with majority having SNHL (19.5\%), followed by mixed (12\%) and conductive in $5 \%$.Mild degree of hearing impairment was present in majority $(27 \%)$ and moderate in $8.4 \%$, whereas moderately severe hearing loss was found only in $1 \%$ of the hypothyroid patients. Severe and profound hearing impairment was not found in any case.

MK Aggarwal et $\mathrm{al}^{[15]}$ showed39\% had hearing loss with $15 \%$ cases had sensorineural, $8 \%$ conductive and $13 \%$ mixed and most of them had mild to moderate hearing loss. Similar findings were found by Dokianakis et $\mathrm{al}^{[16]}$, showing moderate SNHL in 8 patients and MHL in 4 of 23 hypothyroid patients. Karlos Thiago et al ${ }^{[17]}$ also showed predominance of SNHL with mild to moderate hearing impairment. In patients having sensorineural or mixed hearing loss, the neural involvement can be explained by biochemical, 
metabolic or morphological changes in the nervous system, thus altering the nerve conduction and presenting neural hearing loss In patients with sensory loss the low levels of thyroid hormones affect the different components of cochlea and thus produce sensory deafness.

The conductive impairment in hypothyroid patients may be the result of reduced compliance due to hypertrophy and oedema of the Eustachian tube leading to Eustachian tube catarrah. Myerhoff (1979) ${ }^{[18]}$,based on experimental study pointed towards changes in ossicles and round window or oval window like crystallized consistency of bone, fusion or distortion of incus and stapes, partial or complete obliteration of oval or round window, as other possible explanations for conductive hearing impairment.

According to Khechinaschvili [19], specific hormone therapy hardly improves either peripheral/central disorder associated with hypothyroidism. Similarly Karlos et al ${ }^{[18]}$ reported there was no relation between the audiometric measurement results and an increase or decrease in $\mathrm{T}_{3}$ or $\mathrm{T}_{4}$ or TSH level. However, Anand et al ${ }^{[12]}$, claimed that audiometric changes seen in hypothyroidism might improve with treatment but brainstem electric response audiometry (BAEP), would be permanent despite the treatment. But, Dilorenzo et $a{ }^{[20]}$ proved by BAEP that the hearing loss in hypothyroid patient improved after hormone replacement therapy.

In our study most of the patients with hypothyroidism were on treatment more than 3 years. However, It is seen that there is no relation between duration of hypothyroidism and $\mathrm{CV}$ symptoms. More comprehensive studies are required to evaluate the reasons of hearing loss during euthyroid period in patients with acquired hypothyroidism.

\section{Conclusion}

The present study was carried out on 100 hypothyroid patients on treatment with euthyroid status. It was found that majority of the hypothyroid patients had no symptoms however, hypothyroidism affects the ear at multiple sites producing various types of hearing impairment, with predominance of sensorineural hearing loss followed by mixed and conductive type, ranging from mild to moderate in severity. Vestibular system was found to be affected only minimally. It was seen that there is no relation between duration of hypothyroidism and cochleovestibular symptoms.

\section{References}

1. W. R. Kemp, "Deafness in Myxoedema," British Medical Journal, Vol. 1, 1907, p. 375.

2. Bagcchi, Sanjeet. "Hypothyroidism in India: more to be done." The lancet. Diabetes \& endocrinology 2.10 (2014): 778-778.

3. Ritter FN. The effects of hypothyroidism upon the ear, nose and throat. Laryngoscope. 1967;77:1427-79.

4. Ben-Tovim R, Zohar $\mathrm{Y}$, Laurian N, Laurian L, Zohiar S. Auditory brain stem response in experimentally induced hypothyroidism in albino rats.Laryngoscope. 1985;95:982-6.

5. Vanasse M, Fisher C, Berthezene F, Roux Y, Volman G, Mornex R. Normal brainstem auditory evoked potentials in adult hypothyroidism. Laryngoscope. 1989;99:302-6.

6. Oliveira JAA. Fisiologia da Audição Cócleaativa In: Figueiredo MS. Emissões Otoacústicas e BERA. São José dos Campos: Pulso Editorial; 2003.p.1-34.

7. Di Lorenzo L, Foggia L, Panza N, Calabrese MR, Motta G, Tranchino G, et al. Auditory brainstem response in thyroid diseases before and after therapy. Horm Res. 1995;43:200-5.

8. Vant Hoff W, Stuard DW. Deafness in myxedema. O J Med. 1979; 48: 361-7.

9. De Vos JA. Deafness in hypothyroidism. Journal of Laryngology and Otology.1963; 77: 390-414. 
10. Rubenstein M, Rubenstein C, Theodor R. Hearing dysfunction associated with congenital sporadic hypothyroidism. Annals of Otology, Rhinology and Laryngology.1974; 83: 814-19.

11. Mc Mohan BJ. Influence of constitutional factors in ontological conditions. Annals of Otolaryngology.1947:56: 298-304

12. V.T.Anand, S.B.S.Mann, R.J.Dash, et al., "Auditory INVESTIGATION IN Hypothyroidism," ActaOto-Laryngologica (Stockholm), Vol. 108, No. 1-2, 1989,pp.83-87.

13. Bhatia PL et al. Audiological and Vestibular function tests in hypothyroidism. Laryngoscope. 1977: 87: 2082-9.

14. Howarth AF, Lloyd HE. Perceptive deafness in hypothyroidism. British Medical Journal.1956; 1: 431-433.

15. M. K. Aggarwal et al. Audiological Evaluation in Goitrous Hypotyhroidism .International Journal of Otolaryngology and Head \& Neck Surgery, 2013, 2, 201206 http://dx.doi.org/10.4236/ijohns.2013.25042

16. Dokianakis G, Ferekidis E, Pantazopoulos P. Hearing loss and hyperthyroidism (author's transl). Arch Otorhinolaryngol 1978;219:351-3.

17. Santos, Karlos Thiago Pinheiro dos, et al. "Audiologic evaluation in patients with acquired hypothyroidism." Brazilian journal of otorhinolaryngology 76.4 (2010): 478-484.

18. Meyerhoff WL. Hypothyrodism and the Ear .Laryngoscope.Oct 1979; 89(10 Pt.2 ; Suppl.19): 1-25.

19. Khechinaschvili, S., et al. "The hearing system under thyroid hypofunction." Georgian Med News 144 (2007): 30-3.

20. Di Lorenzo, L., et al. "Auditory brainstem responses in thyroid diseases before and after therapy." Hormone Research in Paediatrics 43.5 (1995): 200-205. 